\title{
Factors Associated with the Detection of Childhood and Adolescent Cancer in Primary Health Care: A Prospective Cross-Sectional Study
}

This article was published in the following Dove Press journal: Journal of Multidisciplinary Healthcare

\author{
Quenia Camille \\ Soares Martins $\mathbb{D}^{1,2}$ \\ Fábia Cheyenne \\ Gomes de Morais Fernandes ${ }^{2}{ }^{2}$ \\ Viviane Euzébia \\ Pereira Santos $\mathbb{D}^{1}$ \\ Ingrid Guerra Azevedo $\mathbb{D}^{2,3}$ \\ Lamech Simplício \\ Góes de Carvalho Nascimento ${ }^{2}$ \\ Cynthia Cibelle \\ dos Santos Xavier (iD ${ }^{\prime}$ \\ Silvana Alves Pereira ${ }^{1,4}$ \\ 'Federal University of Rio Grande do \\ Norte, UFRN, Natal, Brazil; ${ }^{2}$ Ana Bezerra \\ University Hospital, Federal University of \\ Rio Grande do Norte, UFRN, Natal, \\ Brazil; ${ }^{3}$ Departamento de Recursos \\ Terapeuticos, Universidad Católica de \\ Temuco, Temuco, La Araucania, Chile; \\ ${ }^{4}$ Public Health Program of the Federal \\ University of Rio Grande do Norte, \\ FACISA/UFRN, Natal, Brazil
}

Background: The treatment of childhood cancer has achieved important advances evidencing a significant increase in overall survival; however, the diagnosis of these cases still seems late. Among the main causes for the delay in diagnosis are the issues related to the health system and the first professional who performs the care. The objective of this study is to evaluate the knowledge of primary care physicians and nurses about the most common signs and symptoms of pediatric cancers, as well as the factors related to the obtained scores. Methods: This is a prospective cross-sectional study, developed in municipalities in the northeastern region of Brazil. Fifty-one professionals (physicians and nurses) were interviewed through a questionnaire structured as a quiz game about knowledge, training and attitudes regarding the signs and symptoms of childhood cancer. Multiple linear regression analysis was used to evaluate the effect of professional characteristics on the number of correct answers on the implemented questionnaire on knowledge of childhood and adolescent cancer.

Results: In the bivariate analysis, the results indicated that the type of employment relationship influences the number of correct answers in the questionnaire used. However, when adjusted for covariates, only the professional category, which means being a medical professional, showed a significant effect on the number of correct answers $(\beta=-7.50, p=0.001)$.

Conclusion: The type of employment relationship of medical professionals and nurses working in primary care had an influence on the number of correct answers for knowledge of childhood and adolescent cancer, but only the professional category (physician) was associated with the highest number when controlled by covariables, thereby justifying the need to improve the curricular training of nurses and greater investments in primary health care for continuing health education that includes infant and adolescent oncology.

Keywords: primary health care, early diagnosis, cancer

\section{Introduction}

The worldwide incidence of childhood cancer has been increasing and has become the leading cause of disease-related mortality in children in developed countries. ${ }^{1}$ It is estimated that more than 160,000 children and adolescents are diagnosed with cancer each year, with more than two-thirds of them living in countries with limited resources. ${ }^{2}$ Even with advances in treatment and an increase in the overall survival rate to approximately $80 \%$ over 5 years for childhood cancers, it still remains the second leading cause of death in children aged 5 to 14 years in low- and middle-income countries, such as Brazil. $^{3,4}$
Correspondence: Silvana Alves Pereira Universidade Federal do Rio Grande do Norte, Departamento de Fisioterapia, Campus Universitário Lagoa Nova, CEP 59078-970, Caixa Postal 1524, Natal, RN, Brazil

Tel +55849918I 8144

Email apsilvana@gmail.com 
Considering the advances already made in the care of childhood cancer, it is possible that the diagnosis is still late. Patients die on average one month after confirmation of the diagnosis, evidencing that investments in both knowledge of risk factors for an early diagnosis and better qualification of professionals could lead to preventing these occurrences and elevated survival rates. ${ }^{5}$

Authors currently divide the diagnostic latency period (waiting time) between the patient's interval to notice the first symptoms related to the cancer and the first visit to a doctor or health professional, and the diagnostic interval (period from the first medical visit until a definitive diagnosis of cancer). ${ }^{6,7}$ Age, histological type of tumor and anatomical location, presence of non-specific symptoms and qualification of the first professional who performed the care are identified as determinants for the diagnosis time. ${ }^{8}$ In this perspective, the parents' knowledge about signs and symptoms, the health system and the sociodemographic differences is listed as factors related to this process. $^{7-9}$

Primary care generally plays a key role in diagnosing childhood cancer, and the first area of care for patients diagnosed with cancer in most countries. ${ }^{10}$ Studies show that the first contact of patients diagnosed with childhood cancer occurred in primary care. ${ }^{11-14}$ During this first contact, the patients were assisted by a physician (68\%) or a nurse $(32 \%) .{ }^{11}$ However, another study verified that diagnostic errors seem more common in primary care when compared to the diagnosis performed in departments of other levels of the health system. ${ }^{12}$

Professionals involved in primary care should possess a high degree of suspicion as well as excellent physical examination skills in order to improve the chances of an early diagnosis of childhood neoplasms. In addition, these professionals should be adequately informed about the signs and symptoms that may be caused by cancer and where to refer patients to carry out the necessary investigations and treatment. ${ }^{14-16}$

However, the knowledge of these professionals does not seem to correspond to the care needs of these patients. A recent study with medical students at the end of the year indicates a low level of memory regarding oncology learning and their recognition of childhood cancer signs and symptoms, especially regarding central nervous system (CNS) tumors. ${ }^{17}$ Even with different teaching approaches, it turns out that students after one year do not retain half of the knowledge gained in disciplines such as pediatrics, and have few opportunities for reinforcement throughout the course. ${ }^{18}$ The same problem can be identified among nurses $^{19}$ and other health workers in primary care. ${ }^{20}$ Moreover, few studies show the gaps in knowledge among these professionals with regard to primary care. The objective of this study was to evaluate the knowledge of primary care physicians and nurses about the most common signs and symptoms of pediatric cancers, as well as the factors related to the obtained scores.

\section{Methods}

A prospective cross-sectional study evaluating the knowledge of physicians and nurses that work in a family health team unit about signs and symptoms of childhood cancer and the factors related to the correct answers. The study protocol was approved by local ethical committees (Committee of the Federal University of the Faculty of Health Sciences of Trairí under no. 352.845 - UFRN). The reference number for the ethics committee is 352.845 . The committee evaluated the ethical aspects of the study in accordance with The World Medical Association's Declaration of Helsinki. The study was explained in detail to the participants. Written and verbal consent was obtained from all professionals included in the study.

\section{Setting}

The right to health in Brazil is the duty of the state and is guaranteed to the Brazilian population through the Unified Health System (SUS), which proposes universal, integral, egalitarian and intersectoral access to actions and services for the promotion, protection and recovery of health at the three care levels: Primary, Secondary and Tertiary. Family health teams are recognized as primary care and work through the Basic Health Units of each municipality, considered the main gateway of SUS, since the population's first contact with the health system takes place at this level of care. These teams work with health promotion, prevention, recovery, rehabilitation and health problems. ${ }^{21}$ The present study was conducted in municipalities of the Trairí region, located in the interior of Rio Grande do Norte, Northeastern Brazil, comprising a population of 100 thousand inhabitants, divided into 10 municipalities and 39 primary healthcare family health teams. ${ }^{22}$

\section{Participants}

Medical professionals and nurses who worked in the 39 Family Health Strategy teams of the state of RN and who agreed to participate in the study by signing the Informed Consent Form (ICF) were considered as inclusion criteria. 
Professionals who worked in primary care less than 6 months until the data collection date were excluded, considering that they could not represent the contingent to be surveyed.

\section{Recruitment}

Seventy-five (75) professionals from 39 teams were selected; however, 13 refused to participate in the study, 1 was on vacation, and 10 were excluded because they had less than 6 months of work in Primary Care. The sample consisted of 51 professionals, 30 nurses and 21 physicians.

\section{Questionnaire Content}

The questionnaire included questions which contained symptoms of childhood cancer, such as: fever, skin paleness, weight loss, abnormal bleeding without definite cause, generalized pain, adenomegaly, headache, nausea and vomiting, bone or joint pain, leukocytosis, thrombocytopenia, severe anemia, mediastinal mass, recurrent chronic abdominal pain, palpable abdominal mass, hematuria, Cushing's syndrome, convulsive crises, altered level of consciousness, increased abnormality in the head circumference, proptosis, gait alteration and coordination, leukocoria, vision changes (diplopia, anisocoria), somnolence, testicular volume increase and arterial hypertension. There were 9 items to identify symptoms of acute leukemia, 6 items for Lymphoma symptoms, 8 items for Abdominal Tumor symptoms, 10 items for Central Nervous System (CNS) tumor, 6 items for Eye Tumor, 2 items for Bone Tumor and 4 items for soft tissue tumor. The score was based on the number of correct signs and symptoms attributed to the respective type of cancer. The application of this questionnaire was individual in the workplace of each participant, with an average collection time of 30 mins.

\section{Measurements}

A structured questionnaire was used based on the recommendations proposed by the Ministry of Health, National Cancer Institute. ${ }^{23}$ The questionnaire consisted of 45 questions about sociodemographic information, including age (years), date of birth, gender (female, male), education level (doctor or nurse), time since graduation, postgraduate area, type of employment (if temporary contract or civil servant), weekly workload (in hours), and how many jobs. Another block consisted of questions about their clinical practice and performance in the Family Health Strategy (FHS).

In this block, the professionals' working time in the FHS, time working in growth and development consultations (c and D) was investigated, as well as if they had participated in any training on cancer and juvenile cancer, and if so, please specify how many times, how long and who promoted the training, and whether this training was prior to or during their work at the FHS. Another question referred to what contribution this training has brought to their professional development and whether they had learned about juvenile cancer during their academic training. The professionals were also investigated to find out if they had any difficulty in making the diagnosis of childhood cancer and in subsidizing this diagnostic hypothesis, and what that was; if in their service had they found any difficulty to refer the child with cancer; moreover, for the child with suspected cancer, what would be the maximum waiting time they would tolerate for referral to the specialist. What conducts would they adopt to communicate the diagnostic suspicion to the relative of the child or adolescent?

\section{Data Collection Procedures}

The professionals were previously contacted by telephone, and invited to an interview to apply the questionnaire and quiz. All interviews were conducted in the presence of two researchers who provided all available information and lasted an average of less than 30 mins.

\section{Power Calculation and Statistics}

The sample calculation was performed based on a descriptive study that evaluated the knowledge of health agents about signs and symptoms of childhood cancer, ${ }^{20}$ and the average accuracy of the study was $40 \%$. Considering a sampling error margin of $10 \%$ and a significance level of $95 \%$, a minimum of 48 professionals was required, considering a percentage of $20 \%$ for eventual losses. Figure 1 shows the sample flowchart.

Data were stored in a database and statistical analyses were performed using the Statistical Package for Social Science (SPSS) 22.0. Continuous variables were expressed as mean and standard deviation for those with normal distribution, or as median and interquartile ranges for those with non-parametric distribution. Categorical variables were expressed as percentages and absolute numbers, while the Kolmogorov-Smirnov test was used to evaluate the normality of the distribution of variables.

Bivariate analyses were performed between the number of correct responses and professional category with the other characteristics of the sample through the Mann-Whitney and Spearman tests. In addition, the chi-square test was performed to compare proportions between categorical variables. 


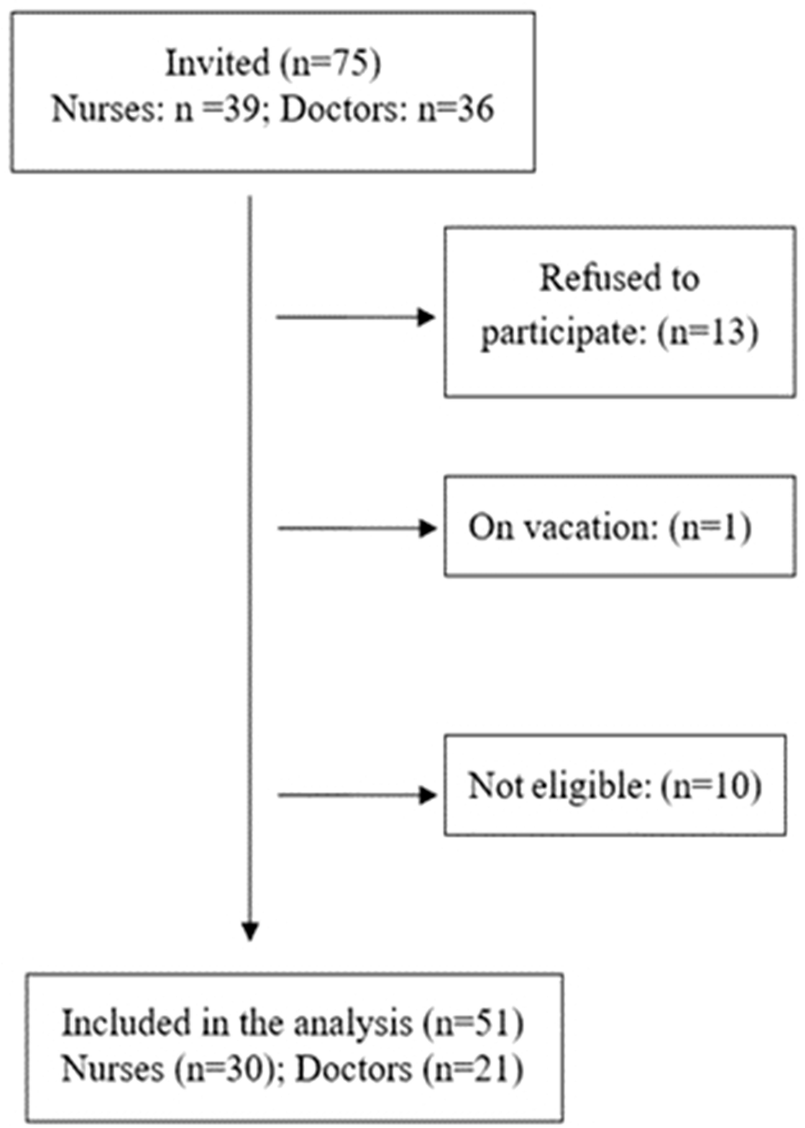

Figure I Flowchart of the inclusion process of health professionals. Notes: Research data, Santa Cruz, 2013.

A multiple linear regression model was used to determine the effect of professional characteristics on the number of correct answers in the questionnaire used to measure knowledge of the most common signs and symptoms in childhood and adolescent cancer. The variables that were significant in the bivariate model $(\mathrm{p}<0.20)$ were included in the regression model. We considered $\mathrm{p}<0.05$ and $\mathrm{CI}=95 \%$ for all the steps. In addition, regression diagnoses were performed for all linear analyses, including collinearity tests, and no significant deviations were observed.

\section{Results}

We interviewed 51 professionals (doctors and nurses). Table 1 shows the profile of the professionals, as well as their work contract characteristics in primary health care.

Regarding the time since graduation, the medical professionals had $2(1-6)$ years on average and the nursing professionals had $4(2-5.75)$ years, while the medical professionals had worked in the FHS for 8 (5-36) months on average, and the professional nurses had worked for 22 (10.7-57) months.
Regarding academic training with an emphasis on childhood and adolescent cancer, 49\% $(n=25)$ of the professionals did not obtain basic education on the subject, with $56.7 \%(\mathrm{n}=17)$ nurses and $38.1 \%(\mathrm{n}=8)$ physicians.

For participation in training on the signs and symptoms of childhood and adolescent cancer, it was observed that only $29.4 \%(n=15)$ received information on this topic; $11.8 \%(n=6)$ achieved this knowledge prior to their enrollment in the Family health strategy (FHS), while 5.9\% $(n=3)$ received training during their time in primary care.

According to data collected about the professionals' knowledge of the signs and symptoms of the main groups of childhood and adolescent cancer, Table 2 shows the median score was $28(62.2 \%)$, and the physicians presented greater assertiveness when compared to the nurses.

A bivariate analysis was performed considering variables related to the profession and contract in the FHS with the total correct responses, and only the contract type (temporary $\mathrm{x}$ fixed) presented statistical significance $(\mathrm{p}=0.028)$. Possessing a postgraduate course $(\mathrm{p}=0.13)$ and the number of employment contracts $(p=0.30)$ did not present statistical significance. Table 3 shows a bivariate analysis for total correct responses considering time since graduating (years), weekly workload (hours) and time working in the FHS (months).

Only the type of profession influenced the number of correct answers for knowledge of childhood and adolescent cancer in the linear regression model, as is shown in Table 4.

\section{Discussion}

With the objective of evaluating the knowledge of primary care physicians and nurses on the most common signs and symptoms of pediatric cancers, our results highlight that only the category of medical professionals was associated with the highest number of correct answers. The academic training of physicians and nurses can positively or negatively influence the time and quality of diagnosing childhood cancer.

Given the generalist training profile of both of the above categories, adequate, timely and correct referral by the general practitioner to primary care is a highly associated factor to the diagnosis time interval, and professionals can accelerate the affirmation process or not of cancer in childhood through their knowledge and experience. ${ }^{24}$ Epidemiological evidence from England indicates that one in five patients seen in general practice and subsequently diagnosed with cancer require three or more visits to the health service so that relevant symptoms are considered for referral to a specialized evaluation. ${ }^{25,26}$ 
Table I Characteristics of the Sample of Professionals Contracted by the Family Health Strategy Program, Rio Grande do Norte, Santa Cruz. 2013

\begin{tabular}{|c|c|c|c|c|}
\hline Variables & Doctor $(n=2 I)$ & Nurse $(n=30)$ & P-value & Total $(n=5 I)$ \\
\hline \multicolumn{5}{|l|}{ Gender } \\
\hline Female & $7(33.3)$ & $25(83.3)$ & $<0.00 I^{\mathrm{a}}$ & $32(62.7)$ \\
\hline Male & $14(66.7)$ & $5(16.7)$ & & $19(37.3)$ \\
\hline Age (years) $*$ & $33.5(11.4)$ & $32.4(9.54)$ & $0.78 \mathrm{I}^{\mathrm{b}}$ & $32.8(10.2)$ \\
\hline Time since graduating (years) ${ }^{\dagger}$ & $2(1-6)$ & $4(2-5.75)$ & $0.101^{\mathrm{b}}$ & $4(2-6)$ \\
\hline \multicolumn{5}{|l|}{ Post-graduate course } \\
\hline Yes & $10(47.6)$ & $22(73.3)$ & $0.062^{\mathrm{a}}$ & $32(62.7)$ \\
\hline No & II (52.4) & $8(26.6)$ & & $19(37.3)$ \\
\hline Time spent conducting Growth and Development consultations (months) ${ }^{\dagger}$ & $8(5-24)$ & $22(9.5-57)$ & $0.016^{\mathrm{b}}$ & $19(8-40.5)$ \\
\hline Time spent working in the Family Health Strategy (months) ${ }^{\dagger}$ & $8(5-36)$ & $22(10.7-57)$ & $0.027^{b}$ & $19(8-48)$ \\
\hline Weekly workload in hours* & $34.6(7.2)$ & $35.8(5.6)$ & $0.875^{\mathrm{b}}$ & $35.3(6.35)$ \\
\hline \multicolumn{5}{|l|}{ How many work contracts } \\
\hline Single contract & $9(42.8)$ & $21(70.0)$ & $0.053^{\mathrm{a}}$ & $28(54.9)$ \\
\hline Multiple contracts & $12(57.2)$ & $9(30.0)$ & & $15(29.4)$ \\
\hline \multicolumn{5}{|l|}{ Type of contract } \\
\hline Temporary & $19(90.5)$ & II (36.7) & $<0.000^{\mathrm{a}}$ & $30(58.8)$ \\
\hline Permanent/Public tender & (2) 9.5 & $18(60.0)$ & & $15(29.4)$ \\
\hline
\end{tabular}

Notes: Categorical data presented as n (\%); *Expressed variable with mean \pm standard deviation; ${ }^{\dagger}$ Variable expressed in median and $25-75$ percentiles. ${ }^{a} \mathrm{p}-\mathrm{value}$ for Chisquare test. ${ }^{\mathrm{b}} \mathrm{P}$-value for Mann-Whitney test.

Table 2 Distribution of Correct Signs and Symptoms by Group for Childhood and Adolescent Cancer Prepared by the Professionals Working in the FHS, Rio Grande do Norte, Santa Cruz. 2013

\begin{tabular}{|l|l|l|l|r|}
\hline Variables & Doctor & Nurse & Total & \multirow{2}{*}{ P-value* } \\
\cline { 2 - 4 } & $\mathbf{N = 2 1}$ & $\mathbf{N}=\mathbf{3 0}$ & $\mathbf{N}=\mathbf{5}$ I & \\
\hline Acute leukemia & $8(7-9)$ & $7(5.75-8)$ & $7(6-8)$ & 0.012 \\
Lymphoma & $4(3-5)$ & $3(2-5)$ & $3(2-5)$ & 0.004 \\
Abdominal & $6(4.5-6.5)$ & $4(2-5)$ & $5(3-6)$ & 0.006 \\
tumor & & & & \\
CNS Tumor & $8(7-9)$ & $7(5.7-8)$ & $7(6-8)$ & 0.005 \\
Ocular tumor & $4(3-4)$ & $2(2-4)$ & $3(2-4)$ & 0.010 \\
Bone tumor & $2(1-2)$ & $I(I-2)$ & $I(I-2)$ & 0.301 \\
Soft tissue tumor & $\mathrm{I}(1-2)$ & $\mathrm{I}(\mathrm{I}-2)$ & $\mathrm{I}(\mathrm{I}-2)$ & 0.984 \\
Total correct & $33(28-$ & $25.5(2 \mathrm{I}-$ & $28(24-$ & $<0.00 \mathrm{I}$ \\
answers & $35.5)$ & $29.2)$ & $33)$ & \\
\hline
\end{tabular}

Notes: Categorical data presented as median and $25-75$ percentiles; *MannWhitney U-test.

Table 3 Bivariate Analysis for Total Correct Responses

\begin{tabular}{|l|l|l|}
\hline & \multicolumn{2}{|l|}{ Total correct responses } \\
\cline { 2 - 3 } & $\begin{array}{l}\text { Doctor } \\
\mathbf{n = 2 1}\end{array}$ & Nurse $\boldsymbol{n}=\mathbf{3 0}$ \\
\hline Time since graduating (years)* & $-0.09(0.66)$ & $0.06(0.76)$ \\
Weekly workload (hours)* & $-0.06(0.79)$ & $-0.12(0.53)$ \\
Time working in the FHS (months)* & $-0.03(0.88)$ & $-0.03(0.87)$ \\
\hline
\end{tabular}

Note: *Spearman correlation: $r$ (p).
Table 4 Linear Regression Model to Evaluate the Effect of Professional Characteristics on the Number of Correct Answers on the Implemented Questionnaire on Knowledge of Childhood and Adolescent Cancer $(\mathrm{N}=5 \mathrm{I})$

\begin{tabular}{|l|l|r|}
\hline Variables & $\begin{array}{l}\text { Number of correct } \\
\text { responses } \beta \text { Cl 95\% (Lower } \\
\text { Limit-Upper Limit) }\end{array}$ & P-value \\
\hline Intercept & $25.07(21.31: 28.82)$ & $<0.001$ \\
\hline $\begin{array}{l}\text { Profession } \\
\text { Doctor } \\
\text { Nurse }\end{array}$ & $7.50(3.37: 11.63)$ & $<0.001$ \\
\hline $\begin{array}{l}\text { Have a post-graduate degree } \\
\text { Yes } \\
\text { No }\end{array}$ & $0.11(-3.48: 3.70)$ & 0.949 \\
\hline $\begin{array}{l}\text { Type of work contract } \\
\text { Temporary } \\
\text { Permanent/tenure }\end{array}$ & 0 & \\
\hline
\end{tabular}

Abbreviation: $\mathrm{Cl}$, confidence interval.

This is due to the fact that there is a natural inaccuracy of childhood cancer symptoms, accompanied by the relative rarity of the associated signs and symptoms, which tends to make immediate diagnosis more difficult. This is different from adult cancer, where the diagnostic process can be performed based on risk factors (with prevention, screening 
and early diagnosis). ${ }^{27,28}$ However, screening measures developed for children in secondary care have not been effective or are restricted to a small group of patients. ${ }^{29}$

The results of our study show that the average time of training and acting in the FHS was less than 5 years, indicating a poorly experienced professional profile.

Through programs such as the Primary Care Professional Appreciation Program (Provab) and the More Doctors Program (Mais Médicos), the Federal Government encourages the inclusion of newly graduated doctors into the healthcare network, such as the FHS. ${ }^{30}$ In Brazil, $61.9 \%$ of physicians and $63.9 \%$ of nurses working in the FHS do not have labor/ contract guarantees. ${ }^{31}$ These data may lead to greater job rotation and difficulty in establishing links with the population.

The results of our study show that $49 \%$ of the professionals interviewed did not obtain basic instructions on the subject during their academic training; while $56.7 \%$ of this percentage corresponded to professional nurses.

Corroborating these results, another Brazilian study reveals that nursing professionals did not have sufficient opportunities regarding the care of cancer patients during their training process, so that little was discussed about the particularities of cancer patient care in the academic environment. ${ }^{19}$

In our study, $51 \%$ of the interviewed professionals had access to content with an emphasis on childhood and adolescent cancer during their training, and $61.9 \%$ of these were medical professionals. It is currently understood that the diagnosis of different types of cancer is related to signs and symptoms known as "signatures", which means those that are closely related to a certain type of cancer. In this perspective, a recent study indicates that knowledge and understanding of such signs and symptoms may improve the diagnostic performance of cancer cases, especially in primary care. ${ }^{32}$ These data corroborate a study carried out in Israel showing that initial care by the professional who carried out the consultation influenced the chances of decreasing the latency period of the disease, meaning that when the first visit was directly in the hospital, the latency time was shorter. Similarly, when the physician, and even more specifically the pediatrician, was the first contact professional, a reduction was found for the diagnosis time. The observation made in this study is that patients attended by a pediatrician had a shorter delay in relation to the diagnosis time, and may indicate that these professionals are more aware of the possibility of cancer in this age group. ${ }^{33}$
In general, it is known that the diagnosis time of the disease and the beginning of treatment are of fundamental importance, since it allows greater chances for curing it and for reducing sequelae. ${ }^{10,11,22}$ Another study conducted in Kenya showed an average of 94 days of delay for diagnosing childhood cancer, whereas the delay was on average 6 days for beginning treatment. About $60 \%$ of the patients interviewed for the sample had their first direct contact with primary care, $32 \%$ of whom were attended by nurses, and $68 \%$ of them were attended by a medical professional, where cancer was mentioned as a possible diagnosis for only $12 \%$ of these parents. These delays may reflect an inefficient system of equipment and/or personnel capable of making a correct diagnosis. ${ }^{11}$

In addition to the lack of training of these professionals in relation to cancer patients, $64.7 \%$ of health professionals interviewed in our study did not receive training on the early identification and/or diagnosis of childhood and adolescent cancer, which may aggravate the increase in the correct diagnosis period of the pathology in question. It should be noted that other barriers such as poor pay, lack of time and insufficient resources for qualification need to be considered to support shared attention models. ${ }^{34}$

Studies which have addressed this theme $\mathrm{e}^{35,36}$ evidenced the need for professional qualification for early identification of cancer, because even though there are some rare cancers in the age group below 19 years, it should be ensured that children are quickly diagnosed and referenced.

In an integrative review, it was pointed out that the limiting factors in early detection of childhood cancer are a lack of communication between general practitioners and specialists, the issue of care fragmentation, lack of training and consequent unprepared general professionals and the lack of demand from practitioners to seek guidelines, cancer treatment summaries, and cancer care survivorship plans, even though they perceive such tools as useful. ${ }^{37}$

In pediatric oncology, nursing faces challenges for education and work in low- and middle-income countries, which include inadequate financial support for salaries and training, lack of access to academic nursing programs, and cultural and organizational barriers that prevent nurses from being recognized as valuable members of the multidisciplinary team. ${ }^{38}$

De Angelis et al found that the delay in childhood leukemia diagnosis was mainly associated with "medical delay" and the lack of programs of continued medical education, since the diagnosis latency time was reduced in districts of Nicaragua, where specific training on 
childhood cancer programs occurred. According to our results, only $29.4 \%$ of the interviewed professionals participated in training related to detecting signs and symptoms of childhood and adolescent cancer, in which access was given before they joined the FHS for $11.8 \%$ of these professionals, and only $5.9 \%$ had this training during their time in Primary Care. ${ }^{35}$

In addition to the lack of investments in continuing education, the rotation of nurses and doctors in primary health care is another point that harms care comprehensiveness and developing employment relationships, which encompasses dimensions such as affectivity, therapeutic relationship and continuity in treatment between professionals and the population, and are indispensable to the quality of care offered, which can compromise organizational efficiency. ${ }^{39}$

Njuguna et al believe that medical practices that prevent physicians from working full time in public hospitals hamper their ability to suspect or even make a correct diagnosis, thereby causing delays in the system and thus contributing to increased health spending. ${ }^{11}$

In addition to the instability in the employment relationships observed in this study sample, just over half of the professionals only worked in the FHS, while the others had between two and four contracts. This data corroborates the study by Pinto, 2010, which found that $31 \%$ of the FHS team members had other work contracts, and justify this need due to the instability in the contracts with the FHS. ${ }^{40}$ In addition, the high turnover and the low availability of professionals for the demands of primary health care, especially the physician, are two important difficulties. ${ }^{39}$

In the perspective of knowing the difficulties of the health services, $60.8 \%$ of the professionals find or have already found some difficulty to carry out or subsidize the diagnostic hypothesis of childhood and adolescent cancer. In the study conducted by Dang-Tan et al it was reported that the health care system delay may be influenced by systemic variables of the health services, and may be longer depending on the quality of these services. ${ }^{27}$

For Ward et al, much of the increased incidence of pediatric cancer survivors is associated with the late effects of cancer treatment such as the use of radiation therapy. These authors further stated that the mean latency time between the primary cancer diagnosis and the subsequent malignancy varied from 9 years for a diagnosis of leukemia, and 23 years for diagnosis of colorectal cancer. ${ }^{4}$
Delayed diagnosis with subsequent delays in establishing adequate treatment can lead to numerous unfavorable consequences for children and adolescents with cancer. ${ }^{40}$ This implies in using more aggressive therapies, the onset of metastasis and the disease evolution. ${ }^{41}$

On the other hand, advances in clinical and biological characterization with the consequent development of adequate therapies and optimization of the provided services have resulted in a considerable increase in curing childhood cancer. ${ }^{2}$

Our results corroborate the findings of Johnson et al, reinforcing the need for individual policies adapted to the reality of a developing country. ${ }^{42}$ Survival in the 1960 s in developed countries was less than $30 \%$ of the affected population, which increased to $80 \%$ in the $2000 \mathrm{~s}$, and the positive result of this work is care integration and investment in research in the pediatric oncology area.

Federal programs and policies in Brazil such as the National Policy for Comprehensive Child Health Care (PNAISC) developed by primary care professionals seek to ensure comprehensive and wide-reaching care for children from pregnancy to nine years of age. ${ }^{43}$ This policy is a further possibility of identifying an early diagnosis of cancer diseases in this age group by recognizing the signs and symptoms of childhood cancer. However, the fact that Primary Care still presents difficulties in this identification ends up significantly interfering in the diagnosis and beginning of treatment, reducing the chances of patient recovery. ${ }^{44}$

In this study we identified that the deficit in the academic training with emphasis on identifying the signs and symptoms of cancer patients, together with the lack of training with continuous education to diagnose childhood cancer can influence the early detection of childhood cancer, thereby causing worse prognoses for cancer patients.

As this is a study conducted in municipalities in the interior of the northeast of Brazil, it is not possible to extend the results to other regions, since there is a diversity in healthcare throughout the country. ${ }^{45}$ However, the results demonstrate the need to promote investments in continuous health education actions, and particularly in cancer care, for the primary healthcare team. This would lead to developing the clinical, critical and up-to-date vision of healthcare professionals, providing an alert for diagnostic screening and guidance for early identification of childhood cancer. There is also the need for prospective studies which contemplate the role of health professionals in early diagnosis of childhood cancer, and an investment in continuing education actions that provide a better reflection on the subject. Furthermore, the shortage found in the academic training 
for pediatric oncology by university institutions should also be emphasized.

\section{Conclusion}

The type of employment relationship of the medical professionals and nurses working in the FHS had an influence on the number of correct answers for their knowledge of childhood and adolescent cancer, but only the professional category (physician) was associated with the highest number of correct responses when controlled by covariables. Thus, it is observed that investments in continuing health education that contemplate oncological attention in the FHS are necessary, along with investments in training that contemplate the team, especially nursing professionals, in order to enable early identification of childhood and adolescent cancer in a timely manner, and further associated with the health networks being structured and organized with this.

\section{Disclosure}

The authors report no conflicts of interest in this work.

\section{References}

1. Terracini B. Epidemiology of childhood cancer. Environ Heal. 2011;10(Suppl1):S8.

2. Rodriguez-galindo C, Friedrich P, Alcasabas $\mathrm{P}$, et al. Toward the cure of all children with cancer through collaborative efforts: pediatric oncology as a global challenge. J Clin Oncol. 2015;33(27): 3065-3073.

3. Kochanek KD, Murphy SL, Jiaquan X. Deaths: final data for 2011. Natl Vital Stat Reports. 2015;63(3):1-120.

4. Ward E, Desantis C, Robbins A, Kohler B, Jemal A. Childhood and adolescent cancer statistics, 2014. CA Cancer J Clin. 2014;64 (2):83-103.

5. Green AL, Furutani E, Ribeiro KB, Galindo CR. Death within 1 month of diagnosis in childhood cancer: an analysis of risk factors and scope of the problem. J Clin Oncol. 2017;35(12):1320-1327.

6. Weller D, Vedsted P, Rubin G, et al. The aarhus statement: improving design and reporting of studies on early cancer diagnosis clinical studies. Br J Cancer. 2012;106:1262-1267. doi:10.1038/bjc.2012.68

7. Whitaker KL, Scott SE, Wardle J. Applying symptom appraisal models to understand sociodemographic differences in responses to possible cancer symptoms: a research agenda. Br J Cancer. 2015;112: S27-S34. doi:10.1038/bjc.2015.39

8. Dang-tan T, Franco EL. Diagnosis delays in childhood Cancer: a review. Cancer. 2007;110(4):703-713.

9. Brasme J, Morfouace M, Grill J, et al. Delays in diagnosis of paediatric cancers: a systematic review and comparison with expert testimony in lawsuits. Lancet Oncol. 2012;13(10):e445-e459. doi:10.1016/S1470-2045(12)70361-3

10. Green T, Atkin K, Macleod U. Cancer detection in primary care: insights from general practitioners. Br J Cancer. 2015;112:S41-S49. doi: $10.1038 /$ bjc. 2015.41

11. Njuguna F, Martijn H, Langat S, et al. Factors influencing time to diagnosis and treatment among pediatric oncology patients in Kenya. Pediatr Hematol Oncol. 2016;33(3):186-199. doi:10.3109/ 08880018.2016.1169566
12. Carberry AR, Hanson K, Flannery A, et al. Diagnostic error in pediatric cancer. Clin Pediatr (Phila). 2017;57(1):11-18.

13. Pritchard-Jones K, Graf N, van Tinteren H, Craft A. Evidence for a delay in diagnosis of Wilms ' tumour in the UK compared with Germany: implications for primary care for children. Arch Dis Child. 2016;101:417-420.

14. Radhi M, Fulbright JM, Ginn KF, Guest EM. Childhood cancer for the primary care physician. Prim Care Clin off Pr. 2015;42:43-55.

15. Fragkandrea I, Alexander J, Helier S, Panagopoulou P. Signs and symptoms of childhood cancer: a guide for early recognition. $\mathrm{Am}$ Fam Physician. 2013;88(1):185-192.

16. Magrath I, Steliarova-foucher E, Epelman S, et al. Paediatric cancer in low-income and middle-income countries. Lancet Oncol. 2013;14 (3):104-e116. doi:10.1016/S1470-2045(13)70008-1

17. Geel JA, Stevenson BT, Jennings RB, et al. Enough is not enough: medical students ' knowledge of early warning signs of childhood cancer. S Afr Med J. 2017;107(7): 585-589.

18. Sullivan PB, Gregg N, Adams E, Rodgers C, Hull J. How much of the paediatric core curriculum do medical students remember? $A d v$ Heal Sci Educ. 2013;18:365-373.

19. Silva JTD, Matheus MCC, FustinoniI SM, Gutiérrez MGRD. Prática profissional de enfermeiras que cuidam de pacientes com câncer em hospitais gerais [Professional practice of nurses who care for cancer patients in general hospitals]. Rev Bras Enferm. 2012;65(3):460-465. Portuguese.

20. Workman GM, Ribeiro RC, Rai SN, Pedrosa A, Workman DE, Pedrosa F. Pediatric cancer knowledge: assessment of knowledge of warning signs and symptoms for pediatric cancer among brazilian community health workers. J Cancer Educ. 2007;22:181-185.

21. Brasil. Ministério da Saúde. Portaria $n^{\circ}$. 2.488, de 21 de outubro de 2011. Aprova a Política Nacional de Atenção Básica, estabelecendo a revisão de diretrizes e normas para a organização da Atenção Básica, para o Estratégia Saúde da Família (ESF) e o Programa Agentes Comunitários de Saúde (PACS). [Approval of the National Primary Care Policy, establishing the review of guidelines and standards for the organization of Primary Care, for the Family Health Strategy (FHS) and the Community Health Agents Program (CHAP). Brasília: Diário Oficial da União; 2011. Portuguese.

22. Brasil. Ministério da Saúde. Banco de Dados do Sistema único de Saúde - Datasus. Cadastro Nacional dos Estabelecimentos de Saúde do Brasil -CNES. 2012. [Unified Public Health System Database Datasus. National Register of Health Facilities in Brazil Disponível em: <http://tabnet.datasus.gov.br/cgi/tabcgi.exe?cnes/cnv/equipern. def $>$. Acesso September 26, 2012. Portguese.

23. Instituto Nacional de Câncer José Alencar Gomes da Silva. Coordenação Geral de Ações Estratégicas. Coordenação de Prevenção e Vigilância. Estimativa 2012: incidência de câncer no Brasil [Internet]. [José Alencar Gomes da Silva National Cancer Institute. General Coordination of Strategic Actions. Coordination of Prevention and Surveillance. Estimate 2012: incidence of cancer in Brazil]. Rio de Janeiro; 2011. 118. Available from: http://www1. inca.gov.br/estimativa/2012/index.asp?ID=1. Accessed March 11, 2020. Portuguese.

24. Ahrensberg JM, Olesen F, Hansen RP, Schrøder H, Vedsted P. Childhood cancer and factors related to prolonged diagnostic intervals: a Danish population-based study. Br J Cancer. 2013;108:1280-1287.

25. Lyratzopoulos G, Neal RD, Barbiere JM, Rubin GP, Abel GA. NoVariation in number of general practitioner consultations before hospital referral for cancer: findings from the 2010 National Cancer Patient Experience Survey in England. Lancet Oncol. 2012; 13:353-365.

26. Lyratzopoulos G, Abel GA, McPhail S, Neal RD, Rubin GP. Measures of promptness of cancer diagnosis in primary care: secondary analysis of national audit data on patients with 18 common and rarer cancers. Br J Cancer. 2013;18:686-690. 
27. Dang-Tan T, Trottier H, Mery LS, et al. Determinants of delays in treatment initiation in children and adolescents diagnosed with leukemia or lymphoma in Canada. Int J Cancer. 2010;126(8):1936-1943.

28. Nehmy RM, Brito AC, Mota JA, Oliveira BM. A perspectiva dos pais sobre a obtenção do diagnóstico de leucemia linfóide aguda em crianças e adolescentes: uma experiência no Brasil [The parents' perspective on receiving a diagnosis of acute lymphoid leukemia in children and adolescents: A Brazilian experiment]. Revista Brasileira De Saúde Materno Infantil. 2011;11(3):293-299. Portuguese.

29. Instituto Nacional de Câncer (Brasil). Diagnóstico precoce do câncer na criança e no adolescente/Instituto Nacional de Câncer, Instituto Ronald McDonald [National Cancer Institute (Brazil). Early diagnosis of cancer in children and adolescents/National Cancer Institute, Ronald McDonald Institute]. - 2. Ed. Rev. Ampl. Rio de Janeiro: Inca; 2011. Portuguese.

30. Barrêto DS, Melo Neto AJ, Figueiredo AM, et al. Programa Mais Médicos e residências de Medicina de Família e Comunidade: estratégias articuladas de ampliação e interiorização da formação médica [The More Doctors Program and Family and Community Medicine residencies: articulated strategies of expansion and interiorization of medical education]. Interface (Botucatu). 2019;23(Supl. 1):e18003230. Portuguese. doi:10.1590/Interface.180032

31. Machado MH. Programa Saúde da Família no Brasil: algumas considerações sobre o perfil dos médicos e enfermeiros [Family Health Program in Brazil: some considerations about the profile of doctors and nurses]. In: Sousa MF, editor. Os sinais vermelhos do PSF [The red signals of FHP]. São Paulo: Editora Hucitec; 2002;12532. Portuguese.

32. Koo MM, Hamilton W, Walter FM, Rubin GP, Lyratzopoulos G. Symptom signatures and diagnostic timeliness in cancer patients: a review of current evidence. Neoplasia (United States). 2018;20 (2):165-174. doi:10.1016/j.neo.2017.11.005

33. International T, Epidemiology C, Haimi M, et al. The role of the doctor and the medical system in the diagnostic delay in pediatric malignancies Cancer Epidemiol. 2011;35(1):83-89. doi:10.1016/j.canep.2010.07.009

34. Lawrence RA, McLoone JK, Wakefield CE, Cohn RJ. Primary care physician perspectives of their role in cancer care: a systematic review. J Gen Intern Med. 2016;31(10):1222-1236.

35. De Angelis C, Pacheco C, Luccini G, et al. The experience in Nicaragua: childhood leukemia in low income countries-the mains cause of late diagnosis may be 'medical delay'. Int $J$ Pediatr. 2012;2012:129707.

36. De Araújo NP, Miranda TOS, Garcia C. O estado da arte sobre a formação do enfermeiro para gestão em saúde. [The art state upon the nurse formation towards healthcare management]. Rev Enferm Contem. 2014;3(2):165-180. Portuguese.
37. Paixão TM, Farias SN, Rosas AM, Coropes VB. Detecção precoce e abordagem do câncer infantil na atenção primária [Early detection and child cancer approach for primary care]. Rev Enferm UFPE Line. 2018;12(5):1437-1443. Portuguese.

38. Rodriguez-Galindo C, Friedrich P, Morrissey L, Frazier L. Global challenges in pediatric oncology. Curr Opin Pediatr. 2013;25 (1):3-15. doi:10.1097/mop.0b013e32835c1cbe

39. Medeiros CRG, Junqueira AGW, Schwingel G, Carreno I, Jungles LAP, Saldanha OM. A rotatividade de enfermeiros e médicos: um impasse na implementação da Estratégia de Saúde da Família [Nurses and doctors turnover: an impasse in the implementation of the Family Health Strategy]. Ciênc Saúdecoletiva. 2010;15(supl.1):1521-1531. Portuguese.

40. Pinto ESG, Menezes RMP, Villa TCS. Situação de trabalho dos profissionais da Estratégia Saúde da Família em Ceará-Mirim [Work situations experienced by Family Health Strategy professionals in Ceará-Mirim]. Rev Esc Enferm USP. 2010;44(3):657-664. Portuguese.

41. Malogolowkin MH, Quinn JJ, Steuber CP, Siegel SE. Clinical assessment and differential diagnosis of the child with suspected cancer. In: Pizzo PA, poplack DG, editors. Principles \& Practice of Pediatric Oncology. 5th ed. Philadelphia: Lippincott Williams \& Wilkins; 2006:165-181.

42. Johnson KJ, Soler JT, Puumala SE, Ross JA, Spector LG. Parental and infantile characteristics and childhood leukemia in Minnesota. BMC Pediatr. 2008;8:7. doi:10.1186/1471-24311-8-7

43. Brasil. Ministério da Saúde. Secretaria de Atenção à Saúde. Departamento de Ações Programáticas Estratégicas. Política Nacional de Atenção Integral à Saúde da Criança: orientações para implementação/Ministério da Saúde. Secretaria de Atenção à Saúde. Departamento de Ações Programáticas Estratégicas. [Health Care Secretariat. Department of Strategic Programmatic Actions. National Policy for Comprehensive Child Health Care: guidelines for implementation/Ministry of Health. Health Care Secretariat. Department of Strategic Programmatic Actions]. Brasília: Ministério da Saúde; 2018. Portuguese.

44. Amorim AA, Carazzi CQO, Brandão EC. Dificuldade dos profissionais de saúde no reconhecimento precoce das doenças oncológicas na infância. [Difficulty of health professionals in the early recognition of childhood oncological diseases].Rev Enferm Faciplac. 2016;1 (1):78-88. Portuguese.

45. Cecílio LCO, Reis AAC. Apontamento sobre os desafios (ainda) atuais da atenção básica à saúde. [Note on the (still) current challenges of primary health care].Cad Saúde Pública. 2018;34(8): e00056917. doi:10.1590/0102-311X00056917. Portuguese.
Journal of Multidisciplinary Healthcare

\section{Publish your work in this journal}

The Journal of Multidisciplinary Healthcare is an international, peerreviewed open-access journal that aims to represent and publish research in healthcare areas delivered by practitioners of different disciplines. This includes studies and reviews conducted by multidisciplinary teams as well as research which evaluates the results or conduct of such teams or healthcare processes in general. The journal covers a very wide range of areas and welcomes submissions from practitioners at all levels, from all over the world. The manuscript management system is completely online and includes a very quick and fair peer-review system. Visit http://www.dovepress.com/testimonials. php to read real quotes from published authors. 